\title{
Sobre o legado de uma arte efêmera: breve reflexão sobre a fugacidade do evento teatral e sua perenidade na memória do espectador a partir do espetáculo "Cour d'honneur", de Jérôme Bel (2013)
}

Rafaella Uhiara ${ }^{1}$

\section{Resumo}

O que resta de uma apresentação teatral após seu fim? O espetáculo Cour d'honneur, de Jérôme Bel, traz à cena as memórias - positivas e negativas - de espectadores de teatro de um determinado espaço, o Pátio de Honra do Palácio dos Papas de Avinhão (França), propondo com esses depoimentos de espetáculos de diversas épocas misturadas uma reflexão sobre a especificidade da mídia teatral em sua relação com a temporalidade e a memória.

Palavras-chave: espectador; teatro; memória; Jérôme Bel; teatro documentário

\section{Abstract}

What remains of a theater show after its last performance? Cour d'honneur stages several happy and not so happy memories of people who attended performances presented in the Cour d'honneur of Avignon Papal Palace at different times. Jérôme Bel proposes with this show to reflect about the specificity of the theatrical medium in its relation to temporality and memory.

Keywords: audience; theater; memory; Jérôme Bel; documentary theater

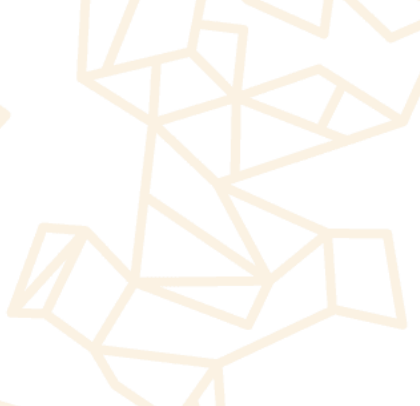

"These our actors, As I foretold you, were all spirits and Are melted into air, into thin air [...]

We are such stuff As dreams are made on, and our little life Is rounded with a sleep." William Shakespeare, The tempest

\section{Introdução: a inexorabilidade do tempo no Pátio de Honra}

Considerando a eventualidade como a essência da natureza do teatro, sendo irredutível a um texto ou uma gravação, o que resta de um espetáculo teatral após os aplausos? "O fechar da cortina é uma morte - uma experiência do fim do tempo" dizia Anne Ubersfeld

\footnotetext{
1 Doutoranda em Estudos Teatrais na Universidade Sorbonne Nouvelle; bolsista CAPES-Doutorado Pleno no Exterior e membro do Laboratório de Pesquisa em Intermidialidade e Artes do Espetáculo do Centro Nacional de Pesquisa Científica da França (ARIAS/CNRS). É mestre em Estudos Teatrais pela mesma universidade (2011) e bacharel em Teatro, habilitada em Direção Teatral, pela Universidade de São Paulo (2007).
} 
(2001, p.21). Porém, o poder de recomeçar - e, por conseguinte, de vencer a morte -, assim como a capacidade intrínseca de criar outras temporalidades, conferem ao teatro certo domínio sobre o tempo, tornando-o lugar mesmo da "provocação do tempo" (UBERSFELD, 2001, p.21). Esse controle se restringe, no entanto, ao único momento que o teatro conhece: o presente. Fugaz, essa "arte do presente" não nos permite experienciar os espetáculos do passado nem guardar as grandes obras da atualidade para a posteridade. Inspirado por esse desaparecimento incontornável das obras cênicas, Jérôme Bel criou o espetáculo Cour d'honneur (2013), objeto de estudo do presente artigo.

\section{O personagem-título}

Cour d'honneur. Pátio de Honra ou, em algumas traduções literais, Corte de Honra. Por que esse espetáculo, que trata de memórias pessoais leva o nome de um lugar? É sabido que um título não é um elemento banal em uma obra, sobretudo de arte contemporânea. Segundo Arthur Danto, "um título é mais que um nome; geralmente é uma orientação para a interpretação ou leitura de uma obra" (DANTO, [1981], 2005, p. 35-36). Segundo este pensamento é possível dizer que o título desvela que o protagonista do espetáculo é o espaço.

Antes do início do espetáculo, o programa entregue aos espectadores revela que a ideia inicial de Jérôme Bel era trabalhar sobre a memória de um lugar, mais precisamente sobre a memória de um espaço teatral. A escolha do espaço não é anódina: cada teatro é carregado de um imaginário diferente. Assim, o Pátio de Honra do Palácio dos Papas foi escolhido, pois, além de ser um lugar carregado de história (ele data do século XIV e foi residência pontifícia nesse século) é também símbolo do teatro francês moderno: da renovação, da descentralização e da popularização do teatro na França, preconizadas por Jean Vilar, criador do Festival de Avinhão. Espaço nobre do Festival, nesse Pátio se apresentaram artistas como Jean Vilar, Bertold Brecht, Pina Bausch, Romeo Castellucci.

Em Cour d'honneur, o discurso sobre o teatro (sobre sua memória e desaparecimento) se cria assim em diálogo com esse lugar, cujos séculos de existência contrastam com a vida curta e efêmera dos espetáculos nele apresentados. Os muros desse Pátio nos fazem lembrar do desaparecimento irremediável não só dos eventos teatrais, mas de nossa própria existência que, assim como o teatro, está predestinada ao desaparecimento. O espetáculo termina, aliás, nesse tom: a memória de uma espectadora, Monique Rivoli, de 66 anos, faz ecoar novamente nos imponentes muros 
do Pátio a voz de Gérard Philippe gravada no LP O príncipe de Hamburgo, de Heinrich von Kleist. Perante a história do ator que morreu prematuramente no auge de sua carreira em 1959 e das demais, ouvidas durante o espetáculo, é inevitável pensar que do evento teatral não sobra nada além de alguns vestígios de sua existência e da memória daqueles que foram por ele transformados.

\section{O autor: introdução à trajetória artística que culminou em Cour d'honneur}

A interrogação sobre a natureza do próprio teatro - seus códigos, seu funcionamento e o sentido de sua existência na sociedade contemporânea - é motor da obra de Jérôme Bel. Coreógrafo de formação, ele não faz diferença entre as linguagens do teatro e da dança: para ele a arte da cena pode ser descrita como "pessoas sentadas no escuro olhando para outras pessoas agindo na luz" (BEL, 2012). Desse modo, Bel cria espetáculos que reduzem a cena a seus elementos fundamentais e desafiam o enquadramento de suas obras nas categorias vigentes.

Em um debate promovido após o espetáculo e aberto ao público foi possível perceber que Cour d'honneur suscitou dúvidas quanto a seu pertencimento à categoria "teatro". Os debatedores apresentavam como motivos principais para esta incerteza: o fato de as pessoas em cena não serem atores profissionais; a ausência de ficção ou algo que transcenda a realidade; ausência de cenário, figurino, efeitos de iluminação; entre outros. Em verdade, como veremos na sequência, nenhum desses aspectos é novo na obra de Jérôme Bel. Cour d'honneur se inscreve na continuidade de suas pesquisas precedentes, acrescida da curiosidade pela memória do evento teatral. O estudo espaço teatral, por exemplo, já havia servido de estímulo criativo para outros espetáculos. Um exemplo é seu primeiro espetáculo dito documentário, Véronique Doisneau (2004), concebido em resposta a um convite do Balé da Ópera de Paris. A obra trazia para a cena do pomposo palácio Garnier o depoimento de uma bailarina mediana oito dias antes de sua aposentadoria. Em um momento particularmente tocante, Véronique dança pela última vez o que ela mais odiou em toda a sua longa carreira: um trecho de O Lago dos Cisnes no qual o corpo de baile passa muito tempo imóvel, compondo o que ela chama de "cenário humano" para dar destaque à primeira-bailarina. Ela pede para o técnico colocar a música e faz sua parte da coreografia, ou seja: ela fica em sua pose imóvel no canto do imenso palco da Ópera de Paris, mas desta vez sozinha no palco nu².

2 Depois desse, outros espetáculos baseados em depoimentos foram feitos com outros dançarinos, dentre os quais destaco Isabel Torres (2005), do Balé do Teatro Municipal do Rio de Janeiro. 
Cour d'honneur surge da mesma curiosidade sobre as pessoas que fazem parte do evento teatral, mas que não ocupam posição de destaque. Ele contava trabalhar sua ideia inicial - a memória de um lugar de teatro - a partir de depoimentos, mas desta vez, de todos os "agentes da representação teatral" (técnicos, atores, encenadores, espectadores, etc.) que teriam assistido ou participado de apresentações no espaço escolhido. Bel se deu conta, no entanto, que, de todos esses, o único que tem a experiência integral do espetáculo é o espectador: tudo é organizado pelos outros agentes para que ele frua com a obra. Bel sempre se intrigou com a relação desses anônimos que, não tendo a arte como prioridade, são um elemento indispensável da arte. O esses espectadores buscam no teatro? Por que eles voltam? Em uma entrevista publicada no programa do espetáculo, Bel assume:

\begin{abstract}
Eu realmente não sabia se os espectadores teriam coisas interessantes a dizer. Se eles tivessem se limitado a dizer: "Eu vi tal espetáculo no Pátio de Honra em 1983, eu gostei, aquela noite foi legal", eu não teria continuado o projeto e talvez eu teria inclusive dado fim à minha carreira, pois, pessoalmente, eu não faço espetáculos para que as pessoas tenham noites legais, eu sou mais ambicioso que isso! O teatro mudou minha vida e é por isso que eu faço teatro profissionalmente. (BEL, 2013b)
\end{abstract}

No entanto, as entrevistas com mais de uma centena de espectadores parecem não ter decepcionado Bel. Os depoimentos escolhidos são bastante heterogêneos e levantam questões, ideias, sensações que nos permitem compreender a vida do teatro do ponto de vista de quem está no lado escuro da sala. Dentre os depoimentos, destacamos o de uma jovem, Alix Nelva, 32 anos, que nunca foi ver espetáculos da programação $I N^{3}$ do Festival por se sentir excluída da elite cultural que a frequenta. Esse depoimento, apresentado justamente no espaço mais nobre do Festival, instiga a reflexão sobre o sentido de estarmos ali reunidos assistindo a um espetáculo em um Festival gigantesco financiado com dinheiro público. Na brochura do Festival de Avinhão, a relação entre a matéria do espetáculo (o espectador) e o lugar escolhido (o Pátio de Honra) se articula da seguinte forma na página sobre o espetáculo de Bel: "Porque era necessário dar ao espectador o lugar que ele merecia: o lugar de honra"4.

30 Festival de Avinhão possui uma programação "IN", na qual alguns poucos grupos conhecidos são selecionados para se apresentarem nos melhores espaços cênicos da cidade,e, e uma programação "OFF", muito mais volumosa que a primeira, mas alheia ao Festival "oficial". Ainda que ambas as programações ocupem a cidade todos os anos no mesmo período, o depoimento de Alix Nelva trata justamente da existência de uma cisão sóciocultural e possivelmente estética entre ambos.

4 "Car il fallait donner au spectateur la place qu'il méritait: la place d'honneur", frase que conclui a apresentação do espetáculo na brochura da $67^{a}$ edição do Festival de Avinhão, 2013, p. 15. "Place d'honneur" é traduzido mais correntemente como "lugar de destaque", mas optamos pela tradução literal para não perder o jogo com o nome do espetáculo e do espaço epônimo. 


\section{O espetáculo, ou "a memória é uma ficção!"}

A "provocação do tempo" se dá de modo bastante peculiar em Cour d'honneur: o espetáculo não só nos transporta a outras temporalidades, mas também cria em cena uma coexistência entre o tempo real, o tempo da memória e o tempo ficcional: o tempo real nos é frequentemente lembrado pela presença desses não-atores em cena, que nos mantém constantemente conectados com a realidade extra-ficcional; quando esses espectadores vêm um a um ao microfone, eles nos transportam para o tempo da memória de suas vivências teatrais nesse Pátio e, finalmente, alguns desses depoimentos são acompanhados da reapresentação das cenas relembradas, com os atores e figurinos dos espetáculos originais, como espécies de ready-mades dentro do espetáculo de Bel. Essa terceira temporalidade é, em verdade, dupla, pois ela traz simultaneamente o tempo de suas ficções - como a Segunda Guerra Mundial, no caso da cena de Apollonia, de Krzysztof Warlikowski - e a época em que se produziu o espetáculo citado (2009, no caso). E, por fim, além da coexistência entre todas essas temporalidades, há também o espaço da lembrança de algo que não aconteceu. É o caso da cena em que Samuel Lefeuvre dança um solo de Wolf, de Alain Platel, espetáculo nunca visto pelo projecionista Pascal Hamant, de 40 anos, e cuja anulação em 2003 o frustrou tanto que ele ainda sente a falta da obra não vista.

O espetáculo se interessa, assim, mais pela memória construída pelo indivíduo do que por uma "descrição histórica fiel" da peça assistida. São justamente os "erros", as transformações que o espetáculo sofre na memória de cada espectador, que interessa Bel. Segundo ele, ninguém se lembra de um espetáculo integralmente, "isso é impossível!" Um bom exemplo disso é o caso extremo do espectador que se apenas se lembra do tédio sentido durante a apresentação de Escola de Mulheres, vista no Pátio em 2001, além da sensação causada pela voz da atriz Agnès Sourdillon:

Eu percebi, depois do espetáculo, que ela [a voz de Agnès Sourdillon] provocava o efeito de um limão. Quer dizer, quando eu como um limão, eu começo a salivar, eu secreto bastante saliva, e a voz da Agnès Sourdillon tem o mesmo efeito em mim.

Depoimentos como esse demonstram que é impossível considerar que há, no teatro, um público homogêneo. Cada espectador fará uma leitura da obra, partindo do que Umberto Eco chama de "enciclopédia pessoal" (ECO, 1962). O caso desse espectador é interessante, pois ele não guardou em sua memória nada que provenha do texto de Molière ou da leitura trazida pela encenação. Assim, o que resta de um espe- 
táculo para cada espectador são apenas fragmentos, momentos marcantes. Como afirma Bel: "A memória é uma ficção!" (BEL, 2012).

Ele se refere ao trabalho como uma “arqueologia do teatro" (BEL, 2012), pois, para ele, a imagem que o espectador terá do espetáculo será reconstituída a partir dos fragmentos que restaram, enquanto todo o resto se esvaiu. Essa "arqueologia", contrariamente ao que se possa imaginar, nos diz mais sobre o futuro dos espetáculos do que sobre o passado do teatro: ainda que Cour d'honneur lide com memórias, portanto, com o passado, o que nos é mostrado em cena é o destino que cada um desses espetáculos teve na memória desses espectadores, as ficções que se criaram a partir desses pedaços de memória.

A reorganização do espetáculo pela subjetividade do espectador não se dá somente pela transformação do espetáculo em sua memória, ou seja, em um tempo futuro ao da apresentação. Em verdade, as obras teatrais já estão entregues a esse grande fator de indefinição que é a subjetividade de cada espectador durante a própria apresentação, no momento presente do espetáculo. No espetáculo de Bel não faltam exemplos disso. Muitos depoimentos mostram as associações que cada espectador pode fazer durante o espetáculo.

Um bom exemplo é o depoimento de Vassia Chavaroche, de 19 anos. No momento em que amanhecia o dia durante Cesena, espetáculo cuja apresentação se iniciava às $4 \mathrm{~h}$ da manhã, a música medieval "chata" escolhida por Anne Teresa de Keersmaeker dava lugar, na cabeça do espectador, aos quatro minutos iniciais do prelúdio de O ouro do Reno, trilha de uma cena que ele gostava muito - também de alvorecer - do filme Nosferatu, de Herzog. Esse é o momento favorito de Jérôme Bel, pois, segundo ele, ele concentra toda sua ideia do espetáculo: ouvir a música que o adolescente imaginava durante o espetáculo nos dá a impressão de poder entrar na sua cabeça, de ver precisamente o que ele estava pensando durante o espetáculo, e de reviver essa experiência junto com ele. (BEL, 2013b)

Outra lembrança do mesmo espectador traz à tona um outro apecto da recepção. Ele viu, aos 14 anos, Inferno, de Romeo Castellucci. De todas as imagens que o marcaram - um piano pegando fogo, Castellucci sendo atacado por cachorros, televisores caindo do alto das janelas do Pátio - a mais forte, para ele, é a do homem que escala o muro gigantesco atrás do palco, cena, aliás, reproduzida em Cour d'honneur. Como ele tinha ido ao festival com uma escola, houve uma discussão depois do espetáculo, e foi dito que, se o palco representava o inferno, esse homem que escala o muro teria conseguido se salvar. Vassia assume, em seu depoimento, que ele não 
havia pensado em nenhuma interpretação; ele apenas sentiu medo: medo que esse homem caísse lá do alto; medo que seu pai escorregue do telhado quando ele sobe para consertar telhas quebradas.

Esse caso simples, assim como acontece em vários outros depoimentos de Cour d'honneur, traz à tona várias questões sobre a natureza do teatro. Uma primeira seria sobre a impossibilidade de se ignorar o "real" (em oposição ao "ficcional") na arte teatral. Como teorizavam Craig (1911) e Maeterlinck (1896), já na virada para o século XX, a realidade se sobrepõe ou mesmo ofusca a ficção ou o simbólico. Desta forma a escalada em Inferno não pode ser reduzida a uma simples semântica: a humanidade do ator, explicitada pelo real risco de vida sofrido por ele, se coloca à frente do universo ficcional. Uma segunda questão seria a oposição entre uma postura interpretativa (como a promovida pela escola de Vassia) e uma recepção sinestésica, que se centra nas sensações do espectador sem se preocupar com o discurso veiculado pela obra, no caso a focalização sobre o medo da queda. A terceira seria o fato de cada espectador criar suas associações mentais extremamente íntimas, como é o caso do jovem que, ao sentir o medo da queda, se lembra do medo de que seu pai morra, elemento alheio ao espetáculo de Castellucci.

Para concluir, o espectador, Bernard Lescure, 67 anos, demonstra em seu discurso como a experiência do teatro é também constituída pelas vivências anteriores que cada espectador teve do teatro. Ele descreve a mesma cena do alpinista de Inferno, apresentado em 2008 no Pátio, usando referenciais espaciais da montagem de Le soulier de satin, de Antoine Vitez, apresentado em 1987. A janela em ogiva, por exemplo, é descrita como o "espaço onde aparece a virgem em Le soulier de satin". Bernard se recorda do momento em que o alpinista desaparece nas alturas como a ascensão da alma de Rodrigue (personagem de Le soulier de satin) ou de Vitez. Ele encerra seu depoimento com a seguinte reflexão: “Será que cada vez que eu venho no Pátio, eu não venho rever Le soulier de satin?".

\section{Conclusão: sobre a matéria do teatro}

Retornamos a reflexão inicial sobre a contraposição entre o tempo fugaz do teatro e a perenidade do Pátio. A imagem do teatro construída por Cour d'honneur é a de uma arte do desaparecimento e da memória. O todo dessa arte se forma assim pela complementaridade entre a fugacidade do evento fugaz e o longo prazo da lembrança dos espectadores. As obras teatrais não podendo ser revistas, o espectador de teatro não pode revisitar os espetáculos assistidos em outras condições e relativizar sua 
recepção. Assim, as obras teatrais são mais suscetíveis de se modificarem na memória de seus espectadores, se distanciando, com o tempo, do espetáculo original. Cour d'honneur propõe justamente olhar para as novas ficções geradas por cada espectador a partir de um espetáculo, como parte da essência dessa arte, assumindo essa aparente fragilidade do desaparecimento como a grande força dessa arte do efêmero.

\section{Referências bibliográficas}

CRAIG, E. G. On the art of theatre. London: William Heinemann, 1911.

DANTO, Arthur. A transfiguração do lugar-comum, [Harvard University Press, 1981]. Tradução de Vera Pereira. São Paulo: Cosac \& Naify, 2005.

ECO, Umberto. Obra aberta, [Milão: Bompiani, 1967]. Tradução de Giovani Cutolo. São Paulo: Perspectiva, 2007.

MAETERLINCK, Maurice. "Le tragique quotidien" in: Le trésor des humbles. Paris: Société du Mercure de France, 1896.

MERVANT-ROUX, Marie-Madeleine. Figurations du spectateur: une réflexion par l'image sur le théâtre et sur sa théorie. Paris, L'Harmattan, 2006.

MERVANT-ROUX, Marie-Madeleine. L'assise du théâtre. Paris: CNRS Éditions, 1998.

UBERSFERLD, Anne. "Le théâtre et le temps" in: Temps scientifique, temps théâtral [atas do colóquio international transdisciplinar de Besançon, realizado de 8 a 10 de junho de 2000]. Besançon: Centre régional de documentation pédagogique de Franche-Comté, 2001, p. 21-24.

\section{Referências audiovisuais (por ordem de citação)}

[BEL, 2013a] Gravação integral de Cour d'honneur, de Jérôme Bel, dirigida por Don Kent / La Compagnie des Indes, produzida por Festival d'Avignon, France Télévisions e Associations R.B. (Jérôme Bel)-Paris, em 19 de julho de 2013, Avinhão, França, duração: 2h. Disponível online no site CultureBox da France Télévisions: http://m.culturebox.francetvinfo.fr/cour-dhonneur-dejerome-bel-au-festival-davignon-2013-139127, consultado em 28 de setembro de 2013.

[BEL, 2012] Entrevista com Jérôme Bel sobre o espetáculo Cour d'honneur realizada pelo Festival de Avinhão no CDC-Les Hivernales no dia 7 de dezembro de 2012, disponível online: http://www.festival-avignon.com/fr/Renc/978, consultado dia 30 de setembro de 2013.

Gravação integral de Véronique Doisneau (2004), Jérôme Bel: http://www.youtube.com/ watch?v=OluWY5PInFs. Difusão do vídeo pelo youtube autorizada por Jérôme Bel e pode ser igualmente acessado em seu catálogo online: www.catalogueraisonne-jeromebel.com, consultado em 30 de setembro de 2013.

Gravação integral de Escola de Mulheres (2001), com Agnès Sourdillon, por Don Kent, produzido pela Compagnie des Indes em 6 de julho de 2001, Avinhão França, duração 1h7min. Disponivel online no site CultureBox da France Télevisions: http://m.culturebox. francetvinfo.fr/lecole-des-femmes-de-moliere-au-festival-davignon-2001-138343, consultado em 30 de setembro de 2013.

Gravação integral de Cesena , Anne Teresa de Keersmaeker, dirigida por Gérard Jan Klaes e Olivia Rochette, produzida por La Compagnie des Indes em 31 de julho de 2012 em Avinhão, França, duração 1h35. Disponível online no site CultureBox da France Télévisions: http://m.culturebox.francetvinfo.fr/cesena-danne-teresa-de-keersmaeker-137577, consultado em 30 de setembro de 2013. 
Gravação integral de Inferno (2008), de Romeo Castellucci, dirigida por Don Kent, produzida por Socìetas Raffaello Sanzio, Festival de Avinhão e La Compagnie des Indes em 8 de julho de 2008, Avinhão, França, duração 2h12min. Disponível online no site CultureBox da France Télévisions: http://m.culturebox.francetvinfo.fr/inferno-de-romeo-castellucci-aufestival-davignon-2008-138349, consultado em 30 de setembro de 2013.

\section{Outras referências}

[BEL, 2013b] Entrevista com Jérôme Bel, realizada por Jean-François Perrier e publicada no programa do espetáculo Cour d'honneur, apresentado na $67^{a}$ edição do Festival de Avinhão, França, 17 a 20 de julho de 2013.

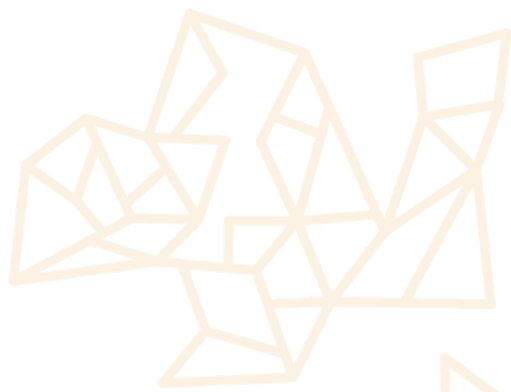

